\title{
O AMBIENTE CULTURAL DE CURITIBA NA DÉCADA DE 1960 E O ARTISTA PLÁSTICO NILO PREVIDI
}

\author{
THE CULTURAL ENVIRONMENT OF CURITIBA IN \\ THE 1960S AND ARTIST NILO PREVIDI
}

\section{Carla Emilia Nascimento*}

\begin{abstract}
RESUMO
O presente artigo pretende expor o ambiente cultural da cidade de Curitiba na década de 1960, a partir de uma discussão que é pautada pelas reflexões surgidas com base nas teorias da cultura, especificamente o enfoque da história cultural. Em um segundo momento, a partir do ambiente artístico, as ações do artista Nilo Previdi (1913-1982), incluindo sua produção no Centro de Gravura do Paraná (1950-1970) são confrontadas com o ambiente cultural exposto. O texto explora a posição de artista engajado assumida por Nilo Previdi em um contexto cultural local, onde há a crescente valorização da arte abstrata, financiada por uma elite dominante na política cultural. A discussão se pauta pelo estudo do contexto histórico da cidade com ênfase no discurso da modernidade, somado aos relatos dos agentes culturais contemporâneos ao artista e a uma análise do debate artístico pautado pelos principais jornais locais.
\end{abstract}

Palavras-chave: Arte paranaense. Arte engajada. Arte abstrata.

\begin{abstract}
This article seeks to expose the cultural environment of Curitiba in the 1960s, from a discussion that is guided by considerations arising from the theories of culture, specifically the focus of Cultural History. In a second step, from the artistic environment, the actions of the Nilo Previdi artist (1913-1982), including its production engraving center of Paraná (1950-1970) are confronted with the cultural environment exposed. The text explores the artist engaged position assumed by Nilo Previdi in a local cultural context, where there is a growing appreciation of abstract art, funded by a ruling elite in cultural policy. The discussion is guided by the study of the historical context of the city - with emphasis on the discourse of modernity - added to the accounts of contemporary cultural analysis to the artist and artistic debate guided by leading local newspaper.
\end{abstract}

Keywords: Art Paraná. Engaged art. Abstract art.

Graduada em Comunicação Social e Graduada em Artes Visuais. Mestre em História. E-mail: carlaemilia.nascimento1@gmail.com 


\section{Introdução}

\section{Um modo para pensar o ambiente cultural da década de 1960}

É pertinente iniciar esta discussão apresentando o lugar de onde ela se origina e quais são os agentes diretamente envolvidos na situação descrita, expondo de que forma alguns conceitos serão explorados a partir dos autores consultados e dos indícios disponíveis.

O cenário da narrativa que se desenrola neste texto é o da cidade de Curitiba na década de 1960, época em os curitibanos frequentavam as salas de cinema, andavam pelas ruas asfaltadas do complexo formado por praças, teatros e biblioteca - inaugurados na década anterior - para discutir os assuntos de última hora dos jornais nos cafés do centro. Esse aspecto será aprofundado no tópico intitulado "A Cidade e o meio cultural", no qual também será exposto o outro lado da urbanidade, que apresenta os cortiços, as favelas, a marginalização e a boemia de uns, aspectos não tão agradáveis aos olhos da sociedade curitibana da época, em relação aos elegantes espaços frequentados por universitários, intelectuais e a elite curitibana ${ }^{1}$.

A fim de contemplar as ambiguidades presentes na década de 1960, que se estendem do aspecto visual da cidade para as relações políticas, econômicas, sociais e culturais, faz-se necessário pensar em uma análise que abarque essas diferenças. Tendo em vista que a especificidade deste texto é pensar a cultura em relação ao meio artístico, a saída aqui encontrada foi a de trabalhar em conjunto os diferentes aspectos que a compõem, utilizando a discussão sobre modernidade proposta por Canclini (2011) e seu conceito de "cultura híbrida", que ele define a partir dos "processos socioculturais nos quais estruturas ou práticas discretas, que existiam de forma separada, se combinam para gerar novas estruturas, objetos e práticas".

\footnotetext{
1 Sugiro a leitura da dissertação Memória e cidade: depoimentos $e$ transformação urbana de Curitiba (1930-1990), de Santos (1995). Baseado na trajetória de vida de seus entrevistados, o autor busca a imagem da cidade através do olhar dos seus habitantes, olhar "marcado pela vida cotidiana: a cidade é um lugar para o lazer, para o trabalho, para os encontros e convivência”. (SANTOS,1995, p. 170).
}

Diversos são os autores utilizados para este exercício interpretativo, Certeau (1995), porém, aparece como pano de fundo presente na discussão para descrever a cidade, o ambiente artístico ou o artista analisado. Este texto empresta as alegorias pensadas pelo autor para discutir a cultura - geograficamente, como que reúne paisagem espaços, diferentes formas de ocupação dos lugares, um ambiente onde se travam lutas por conquistas e onde se caça! Há algo muito importante a considerar: o surgimento da cultura (ou de culturas) nos locais menos improváveis.

Procura-se pensar nos aspectos que Certeau aponta na problemática prática da escrita da história, considerando que essa atividade implica a formação de discursos e que este ato de escrever tende por vezes a eliminar ou a silenciar o outro. Mesmo tentando buscar essa espécie de interdição, no sentido exposto por Foucault (1996), que muitas vezes faz parte da história que pretendemos discutir, esse é um risco sempre presente na pesquisa que se procura realizar. Mais honesto é aceitar o risco desta constatação, a de que não há como ser totalmente parcial, pois o pesquisador sempre fala de um lugar que lhe é próprio.

O personagem escolhido para ser o fio condutor deste estudo permite que se revelem as práticas do conjunto cultural de seu tempo, em que se destacam os processos de interdição pelos quais passou. E é consciente, embora inevitável o fato de que ao deixar Previdi falar, muitas outras vozes estarão sendo silenciadas.

Nilo Previdi (1913-1982), principal personagem desta discussão, foi um artista curitibano que junto com outros de sua época tornou-se um agente importante em processos de ruptura e de instituição, como a de uma suplantação da arte acadêmica por uma arte moderna. Para o leitor menos envolvido com essa problemática, vale a pena ressaltar que até a década de 1950 a arte aceita oficialmente na cidade era aquela de moldes mais acadêmicos. $\mathrm{O}$ artista plástico Jair Mendes ${ }^{2}$ relata um pouco da cidade e da arte que se fazia no período:

Eu cheguei em Curitiba em 1951 [...] e eu fiz o curso de Belas Artes de 54 a 58, [...] foi quando eu

\footnotetext{
${ }^{2}$ Jair Mendes (1938), artista plástico. Entrevista concedida à autora em 1 set. 2011.
} 
conheci o artista Nilo Previdi. Nós vivíamos em um mundo restrito à Curitiba. Curitiba ainda era uma aldeia, quando eu cheguei aqui tinha $200 \mathrm{mil}$ habitantes. É ... nós não tínhamos essa comunicação com o mundo.[...]. Carta demorava, telefone era muito difícil, não tinha imagem, nem revistas, jornais a gente recebia de fora, então esse foi o período de uma arte genuinamente paranaense.

O que o artista chama "arte genuinamente paranaense" é a arte acadêmica citada no parágrafo anterior, ensinada na Escola de Música e Belas Artes (EMBAP), fundada em 1948 e que era aceita pelo Salão Paranaense de Belas de Artes, inaugurado em 1944. Sobre a arte acadêmica, o artista a descreve da seguinte forma:

A pintura ainda só de paisagens ou retratos. Muito pinheiro, porque era o símbolo do Paraná. Então era uma pintura que quando muito avançada aproximava-se um pouquinho do impressionismo, mas nem isso. Então era a pintura que se fazia no Paraná, era aquela. De fundo de cozinha, sabe?

Era justamente a fim de superar a arte de "fundo de quintal" que Previdi pode ser considerado um artista moderno e agente de uma ruptura promovida gradualmente e que em 1957 apresenta-se como um marco ${ }^{3}$. A fermentação de ideias acontecia dentro das instituições como a biblioteca pública e grupos alternativos à intelectualidade da Embap. $\mathrm{O}$ relato a seguir, do artista Ennio Marques Ferreira, ${ }^{4}$ demonstra um pouco dessa agitação cultural na qual se destaca também, já na década de 1950, certa cisão de grupos. No depoimento, o artista cita a galeria Cocaco, uma espécie de molduraria da qual ele era um dos sócios e que passou a representar um ponto de encontro de artistas.

Nesse movimento da Cocaco que coincidiu mais ou menos com esse movimento do Clube de Gravura, era um movimento mais aberto e que se

\footnotetext{
3 Trata-se da ocasião em que os artistas que não mais se adequavam à arte acadêmica vigente se revoltam contra as premiações concedidas pela comissão julgadora do XIV Salão Paranaense, que privilegiaram os artistas acadêmicos. Os revoltosos retiraram suas obras do Salão e depois de muita discussão fizeram uma exposição à parte, intitulada Salão dos PréJulgados. Essa manifestação acabou sendo conhecida, especialmente pelas críticas de arte de Adalice Araújo, como Movimento de Renovação. Após esse episódio, os rumos do Salão Paranaense passariam por alterações e os artistas considerados modernos teriam maior visibilidade. O episódio teve vasta cobertura jornalística. O Estado do Paraná é um dos periódicos que se engajou nessa cobertura. Para maiores detalhes consultar Freitas (2003).

4 Enio Marques Ferreira (1926) entrevista concedida em 5, set. 2011.
}

formou [...] nos anos de 57 e 58 por aí, [...] ali se tornou uma coisa realmente livre, aberta e as pessoas que iam lá se encontravam na Cocaco e ao mesmo tempo tinham lá as exposições da biblioteca pública, tinha os barzinhos aqui em frente e coisas assim. Então aquilo ficou um ambiente bem propício para o desenvolvimento de papos artísticos. [...] Aquele movimento de dentro da Cocaco e que pouco tinha de relacionamento com o Clube de Gravura do [Previdi] e eles participavam lá do movimento porque era onde se reuniam muitos artistas e eles também estavam incluídos nesse grupo, né?

Esse recuo para a década anterior se fez necessário a fim de apresentar a formação de uma composição de ideias que se tornariam opostas na década de 1960. O artista Ennio Marques reconhece a participação de Previdi no círculo de discussões da Cocaco, mas o distingue como pertencente ao Clube de Gravura, um local cheio de significações, que será melhor explorado no tópico "O centro de gravura". Além do mais, Ennio Marques já descreve um pouco das transformações culturais da cidade, que de "aldeia", conforme enfatizado por Jair Mendes na década de 1950, passou a oferecer pontos para fomento e discussão das artes quase uma década depois.

Embora antenado com os diferentes grupos de arte da cidade, o período referido, 1960, é para o artista Nilo Previdi uma época de certa reclusão no meio artístico oficial, em virtude de antagonismos ideológicos entre a arte que ele defendia, especialmente dentro do Centro de Gravura, e aquela imposta pela política cultural dominante, da qual o próprio Ennio Marques fez parte, defendendo a abstração como arte moderna.

A possibilidade de falar de um artista em determinado momento a favor da política cultural vigente e em outro, contrário a ela, indica a existência de um sistema composto de diferentes interesses, que em conflito geram tensões. Tal qual o campo descrito por Pierre Bourdieu (1990), o meio artístico da cidade de Curitiba na década de 1960 se apresenta passível desse tipo análise. Mais do que falar do meio, ou do campo artístico e das instituições, este texto pretende enfatizar o deslocamento dos agentes culturais, entre eles Previdi, a fim de conquistar e legitimar espaços no âmbito cultural. 
Uma discussão do meio artístico da década de 1960, a partir de uma leitura de Certeau (1998, p. 35 ), conduz à procura da delimitação do campo artístico, "narração de práticas comuns, experiências particulares, frequentações, solidariedades e lutas que organizam o espaço onde estas narrações abrem caminhos", e as maneiras de caminhar, conforme expressões do próprio autor.

O entendimento do cenário cultural será discutido na busca pelos trajetos feitos, seja pelos caminhos das vias principais, seja pelas margens ou desvios, para compartilhar da mesma metáfora do "andar na cidade" utilizada por Certeau. Esse exercício permite abordar o contexto, a partir da obra do artista, neste artigo, privilegiando a produção de Previdi no Centro de Gravura.

Finalizando as intenções do texto proposto, vale ressaltar que quando os conceitos para esta discussão são buscados em Michel de Certeau e em Roger Chartier, pretende-se valorizar a obra de arte e os relatos orais como fontes históricas, além de instigar outras possibilidades de pensar a história da arte paranaense, e em específico o que ficou registrado sobre o artista Nilo Previdi e que hoje compõe a sua imagem. Conforme Chartier (2002, p. 91):

[...] o objeto fundamental de uma história que visa a reconhecer a maneira como os atores sociais dão sentido a suas práticas e a seus discursos parece residir na tensão entre as capacidades inventivas dos indivíduos ou das comunidades e, de outro lado, as restrições, as normas, as convenções que limitam - mais ou menos fortemente de acordo com sua posição nas relações de dominação - o que lhes é possível pensar, enunciar e fazer. A constatação vale para a história das obras letradas e das produções estéticas, sempre inscritas no campo das possibilidades que as tornam imagináveis, comunicáveis e compreensíveis [...].

Desse modo espera-se abordar inicialmente o ambiente cultural de Curitiba na década de 1960, tentando compreender a hibridização entre culturas, no sentido exposto por Canclini, incluindo a popularização dos meios de comunicação de massa. Em um segundo momento, intitulado "O meio artístico", pretende-se pensar o contexto a partir da obra artística de Previdi, considerando as forças inerentes ao meio artístico, a ação dos agentes culturais e os discursos produzidos que resultaram na obra de arte analisada e que dela também emanam.

Justifica-se o uso de dois autores franceses, Certeau e Chartier, ambos representantes da história cultural, para a análise do quadro apresentado, em virtude da adequação da proposta de leitura cultural desses autores ao objeto de pesquisa apresentado. Canclini, autor representante dos estudos culturais, está presente nesta abordagem por apresentar um olhar cultural específico para a América Latina, na qual estão presentes as diferenças entre a nossa modernidade e a europeia. O próprio Certeau (1995, p. 230) reconhece a importância do relativismo quando se trata da análise da cultura que é particularizada, afirmando que:

[...] as racionalizações econômicas ocidentais atuam diferentemente ${ }^{5}$ nos países onde as estruturas socioculturais são diversas daquelas que permitiram na Europa, há três séculos, o desenvolvimento das técnicas e das ciências.

Conforme o exposto, reconhece-se neste artigo a distância que separa a situação analisada em Curitiba dos objetos de análise dos estudiosos da cultura francesa. Porém, acredita-se que a contribuição europeia somada à visão cultural de um estudioso latino-americano seja útil para se pensar uma cidade brasileira, a Curitiba de 1960, com suas semelhanças e diferenças em relação aos modelos apresentados por esses três autores.

\section{A cidade e o meio cultural}

A cidade de Curitiba, aqui apresentada, é na década de 1960 um dos exemplos - assim como outras cidades do Brasil - de representação de si, a partir de um discurso de progresso e modernidade iniciado décadas antes, mas que, especificamente para este artigo, traz no âmbito cultural em voga uma mescla de diferentes discussões. No meio estético duas questões se apresentam: a arte engajada, da qual Nilo Previdi é representante, e a arte abstrata, assumida como arte moderna pela elite cultural dominante.

Trata-se, portanto, da análise de dois discursos distintos, ambos surgidos no interior de uma enunciação mais ampla, a da modernidade da cidade. A

\footnotetext{
${ }^{5}$ Grifo do autor.
} 
noção de modernidade pode ser entendida no sentido exposto por Chartier (2002, p.74-75), do qual se extrai que "a representação é exibição de uma presença, a apresentação de uma coisa ou de uma pessoa". Porém, essa exibição nem sempre condiz com seu referente: assim, a imagem da cidade moderna, especificamente a cidade de Curitiba dos anos 1960, não pode ser tida como "a verdadeira", ou a única verdadeira, uma vez que um dos sentidos de representação distinguido por Chartier é o que considera "os sinais visíveis como indícios seguros de uma realidade que não existe", mascarando desta forma uma realidade que é diferente. ${ }^{6}$

Para melhor entender a primeira proposição, que coloca Curitiba como uma cidade moderna, e para entender em relação a quê ela se intitula moderna, Camargo (2002, p. 3-4) traz um panorama que nos servirá para compreender a visibilidade moderna da cidade. $\mathrm{O}$ autor, que discute justamente a questão da arte abstrata no Paraná, situa o desejo de modernização no estado a partir de uma vontade política ainda na década de 1930, estendendo-se para as décadas de 1940 e 1950, em sintonia com resto país.?

Lembramos que na década de 1950 acontece uma verdadeira onda desenvolvimentista, impulsionada em âmbito nacional pelo governo JK. Em Curitiba, principalmente a partir de 1953, ano de seu centenário de emancipação política, é notável o número de obras públicas inauguradas, ruas asfaltadas e alargadas, proporcionando à cidade um aspecto cada vez mais urbano. Não há como ignorar a presença do sentido da modernidade, uma vez que Curitiba se recobre de estátuas, monumentos e símbolos que remetem a essa noção de desenvolvimento e progresso, embora este seja o lado "agradável da cidade moderna".

\footnotetext{
${ }^{6}$ O outro sentido de representação utilizado por Chartier (2002, p. 74) é o que considera a manifestação de uma ausência, "o que supõe uma clara distinção entre o que representa e o que é representado".

${ }^{7}$ Camargo situa a formulação de uma política de modernização do Paraná (econômica e social) na gestão do interventor Manoel Ribas, em 1935, evidenciando já nessa década, a existência de um discurso de modernidade. Porém, vale a pena lembrar que é na década de 1940, através do Plano Agache, que a cidade é reordenada, com um planejamento urbano que previa medidas de saneamento básico, descongestionamento de vias urbanas, criação de áreas de arborização e o planejamento da disposição dos órgãos públicos, incluindo o projeto de construção do centro cívico e outros projetos que seriam visíveis na década de 1950. Consultar: < http:// www.lolocornelsen.com.br>Acesso em 10 mai. 2011.
}

A Curitiba dos anos 1960 se apresenta com esses ares de inovação idealizados em décadas anteriores e sobretudo com ênfase na cidade em oposição ao campo. Somam-se a isso o incremento dos jornais e cinemas, o surgimento de rádios e redes de televisão, além do desenvolvimento das instituições culturais já existentes: a biblioteca, os teatros, os salões de arte, os museus, que merecerão uma atenção especial no tópico "O meio artístico".

Entre os jornais, este artigo enfatiza o caderno cultural de $O$ Diário do Paraná. Trata-se de Letras e/ \& Artes, suplemento do jornal iniciado em 1959 e interrompido em $1961^{8}$. Conforme as palavras de seu editor, Sylvio Back, para uma reedição especial de alguns fascículos, "dele [Letras e/ \& Artes], sobrevive uma bela fortuna crítica de talento, inconformismo e controvérsia", completando que:

Havia naquelas páginas dominicais a dor e o orgulho do saber da província: produzia-se de e para Curitiba. Não havia o flerte e a reverência ao eixo Rio-São Paulo [...] Havia, sim, prioritariamente, o reconhecimento da criatividade emergente local, que, pela primeira vez, encontrava espaço pertinente para revelar sua produção.

Apesar das palavras acima, que evocam uma valorização do local, "produzia-se de e para Curitiba", Letras e/ \& Artes publicava um conteúdo cultural voltado para um público interessado em críticas de teatro, cinema, poesia, artes plásticas, crônicas e filosofia, em um estilo distante da linguagem popular. O mais interessante desses fascículos são as referências à filosofia existencialista, através da tradução de textos, e de discussões em torno dos pensamentos de Sartre ${ }^{9}$. As referências ao teatro engajado também compõem boa parte desse suplemento e essas constatações ajudam a pensar o embate de ideias do período. Se por um lado a arte oficial da cidade, especialmente as artes plásticas voltava-se para a valorização da

\footnotetext{
${ }^{8}$ Segundo Sylvio Back, o caderno cultural acabou quando ele saiu do jornal por liderar uma greve contra o atraso nos salários dos funcionários da TV Paraná, então pertencente ao mesmo veículo de comunicação. Enfatize-se aqui a presença da televisão e dos movimentos populares como o dos trabalhadores reivindicando salários. Consultar Letras e/\& Artes. Cinquenta anos. Diário do Paraná. Edição fac-similar.

${ }^{9}$ Kaminski (2008) traça um panorama do ambiente cultural de Curitiba enfocando a década de 1960 . Na tese apresentada pela autora, discutemse as produções cinematográficas de Sylvio Back, sendo que uma das constatações é a aproximação de Back com os existencialistas, conceito que será explorado neste artigo em relação ao artista Previdi.
} 
arte abstrata, havia outra corrente de pensamento, em sintonia com ideias internacionais, que defendia a arte engajada, a arte com função social.

$\mathrm{O}$ artista Nilo Previdi não chegou a escrever ou publicar trabalhos seus no Letras e/ \& Artes, mas o discurso presente no caderno cultural - no que se refere à valorização da arte como forma de conscientização e a função social do artista - também faz parte do discurso dele e são características fortes na sua atuação, principalmente na década de 1960, no Centro de Gravura. Para Previdi, "o academicismo abstrato ou de outra forma qualquer é principalmente em torno de uma pintura estereotipada que não reflete qualquer sentimento de povo algum e que anula a personalidade do próprio artista". ${ }^{10}$

Se Previdi se manifestava por meio de outros periódicos, o Letras e/ \& Artes tinha em seu quadro de colaboradores outros intelectuais engajados, caso de Walmor Marcelino (1930-2009), conhecido jornalista e militante de esquerda. Além dele, outros críticos de arte e agentes culturais de tendências opostas ao engajamento como Ennio Marques Ferreira também participavam. Apesar da forte inclinação para os assuntos de interesse da esquerda política, o caderno cultural não era partidário, estava aberto à colaboração da intelectualidade da época.

Mas os jornais escritos eram apenas parte dos recursos de informação e entretenimento, além dos cinemas, presentes na cidade desde $1908{ }^{11}$. É exatamente em 1960 que a televisão chega ao Paraná, através da TV Paranaense (canal 12) e da TV Paraná (canal 6). Como era costume na época, toda a programação era feita ao vivo e o mais interessante é que inicialmente contou com o trabalho dos artistas do circo. Estes, antes de serem substituídos como opção de lazer e "perderem um espaço" de entretenimento para a TV, foram os responsáveis por fornecer, ao novo meio, técnicas de atuação em frente às câmeras e pessoal para atuar, dirigir e produzir roteiros. ${ }^{12}$

\footnotetext{
${ }^{10}$ Recorte de jornal sem identificação, presente no acervo no acervo do MAC.

${ }^{11}$ Exibições de imagens já aconteciam em Curitiba desde 1903, através de apresentações itinerantes. Porém, em 1908 é inaugurado o primeiro cinema com apresentações diárias.

${ }^{12}$ Andrioli (2007) conta a história do circo na cidade de Curitiba a partir da trajetória da família Queirolo, circenses de origem uruguaia que se apresentaram em Curitiba pela primeira vez em 1924, fixando-se na cidade duas décadas depois. $\mathrm{O}$ autor expõe o ambiente cultural da cidade desde
}

Um dado curioso e que serve para reforçar o aspecto da fusão entre as práticas culturais reside no fato de que a atração circense não pode ser rotulada como destinada ao público menos culto ou de menor poder aquisitivo, embora isso tenha se tornado realidade durante a década de 1960. Andrioli (2007, p.43), lembra que durante os anos 1940 a principal atração do Cassino Ahú, um dos locais mais luxuosos de Curitiba, eram os números circenses.

Como se percebe, o meio cultural estava composto por uma oferta variável de arte, informação e entretenimento. Permaneceram na cidade os locais mais elitistas de cultura como os teatros que cederam por determinado período espaço para o cinema, até que este adquirisse seu ambiente material próprio. E a arte elitista - de óperas, música clássica e teatro - conviveu com o advento da chamada cultura de massa, o cinema e a televisão, lado a lado com a cultura popular, exemplificada aqui através do circo.

Os indícios acima permitem falar da cultura diversificada da cidade, entendendo a impossibilidade do isolamento de uma manifestação pura, abrindo mão da oposição entre cultura erudita e popular e do julgamento que advém desse tipo de análise e que tende a sobrepor uma à outra. Para tanto se reconhece uma cultura formada pelos interstícios entre os espaços comuns das três culturas distintas: a elitista, a midiática e a popular, sendo possível falar delas em separado (uma leitura deficiente), ou como um todo mais complexo.

A opção pela complexidade é defendida neste texto como aquela capaz de revelar as tensões existentes no ambiente cultural. Mais do que discutir as tensões, de acordo com o entendimento do que propõe Chartier (2002), faz-se necessário, a partir dos pontos de conflito, investigar de que forma os diferentes agentes conseguem intervir na realidade que lhes é colocada.

À representação de cidade moderna talvez fosse mais conveniente no século XX a abordagem da cultura midiática como um progresso adquirido e inserido nos costumes da elite curitibana, incluindo aí todo um aparato tecnológico. Mas como abordar o fenômeno como um todo sem considerar a parte

a década de 1940 até praticamente o final da década de 1970, enfocando a atividade e o público de uma arte popular, tão presente quanto poderíamos pensar sobre a arte erudita ou elitista. O circo era, segundo Andrioli, uma alternativa aos teatros e clubes fechados. 
da população que ficou de fora, sem o acesso a essa tecnologia, ou que é incapaz de compreendê-la? Para esclarecer até que ponto se pretende chegar, o discurso entusiasmado do progresso expresso pela urbanização e inovações tecnológicas será agora substituído pela imagem da marginalização de quem ficou de fora nesse processo. Data de 1962 a matéria intitulada "Curitiba ao avesso: os subterrâneos do silêncio", publicada na revista Panorama. Consta na matéria que:

A capital paranaense, exemplo de progresso e nível de vida alto e estável, adentrou irremediavelmente no rol dos melancólicos palcos do contraste social. De Pasárgada, a Capital do Paraná transformou-se num problema. Invadida sua periferia de favelas e cortiços homiziando aglomerados humanos flutuantes, entre 25 a 30 mil infelizes, na maioria do norte do Estado e do país, agora o centro da cidade capitulou ante o ímpeto da miséria e o verso e reverso comovem o mais indiferente. Com a aquiescência das autoridades a tragédia está aí.

A matéria aponta para o forte contraste entre cidade e subúrbio (um subúrbio no centro da cidade!) trazendo imagens que comprovam o abandono das pessoas, muitas "honestas, homens, mulheres e crianças vivendo na base da esperança". No texto, o autor ainda diferencia os cortiços das favelas, estas últimas responsáveis por encaminhar prostitutas e ladrões às ruas. Um dado importante: a menção à migração urbana. Não se trata mais dos estudantes que chegaram a Curitiba em busca da cidade universitária, mas atrás de melhores condições de vida, condizentes com a cidade moderna, em uma relação que é diferente e que, reflete exclusivamente em cima dos postos de trabalho.

A descrição seguinte remete a outra representação de Curitiba, menos interessante às elites dirigentes e, conforme indicação do autor, disfarçadamente margeando o centro comercial:

$\mathrm{O}$ quadro não é fictício. A vinte metros da rua $\mathrm{XV}$ de Novembro, o pulmão de Curitiba, a miséria disfarçada margeia os costados dos prédios e casa com dois a três andares, de construção antiga. $\mathrm{O}$ contraste é brutal: lojas, magazines, relojoarias, bares, restaurantes, bancos, repartições públicas (sinônimos de comércio, consumo, trabalho) acobertam uma outra população, um outro gabarito da vida, resumido na palavra-chave MISÉRIA (protótipo de um irreversível desajuste social). Do alto de um edifício, pode-se vislumbrar os dois mundos. Achegando-se aqueles dos miseráveis, a impressão é profundamente aviltante; eles nem ao menos respiram o ar nosso de cada dia.

Destaque-se uma diferenciação importante discutida por Canclini (2011, p. 67-70), e que diz respeito ao contexto latino-americano, onde ocorreu o processo de "modernismo sem modernização" 13. Trata-se de considerar as modificações sociais e econômicas ocorridas em fins do século XIX e início do XX, que contribuíram para o aumento da alfabetização, o crescimento urbano, a entrada dos estrangeiros migrantes e o advento da própria mídia, entre outros fatores ocasionados pela expansão do capitalismo. Porém, o autor chama a atenção para o fato de que o processo nos países latinos não aconteceu da mesma forma como foi realizado na Europa. No Brasil - e essa situação pode ser bem aplicada ao contexto estudado de Curitiba - não houve a formação de um mercado autônomo para o campo artístico nem a garantia de sua profissionalização.

$\mathrm{Na}$ realidade brasileira não foi possível a formação de públicos para o consumo da arte, incluindo aí a literatura. $\mathrm{O}$ autor ainda enfatiza a necessidade de os artistas buscarem outras funções, em virtude de não conseguirem sobreviver da arte, e essa é uma situação bem explícita em Curitiba quando se percebe que todos os artistas plásticos eram também professores ou possuíam uma dupla função que lhes garantisse remuneração. Sobre essa questão, baseado no mercado literário, o autor afirma:

E durante muitas décadas posteriores, os escritores não puderam viver da literatura, tendo que trabalhar como docentes, funcionários públicos ou jornalistas, o que criava relações de dependência do desenvolvimento literário com relação à burocracia estatal e ao mercado de informação de massa. Por isso, no Brasil não se produz uma distinção clara, como nas sociedades europeias, entre

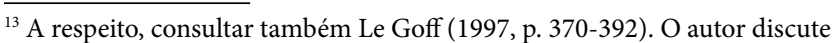
o conceito de moderno, situando o seu aparecimento no século XIX. No século XX ele enfatiza o que chama de "ocidentalização do Terceiro Mundo" e a ideia de modernização [grifo meu]. Não é uma questão simples: (o autor distingue três tipos de modernização. Chamo a atenção para o desenvolvimento econômico e técnico da modernidade, feito de forma distinta do desenvolvimento social e cultural. Outra distinção feita pelo autor e que é bem útil para o contexto estudado é entender a modernidade como uma tomada de consciência das rupturas do passado e o modernismo no âmbito do meio cultural.
} 
a cultura artística e o mercado massivo, nem suas contradições adotam uma forma tão antagônica. (CANCLINI, 2011, p. 68)

É possível pensar essa mesma problemática voltada para as artes plásticas, em que o reconhecimento dos artistas plásticos estava atrelado à visibilidade adquirida através do Salão Oficial de Arte. ${ }^{14}$ Depois disso vinha o reconhecimento da sociedade, com os jornais atuando como veículos para a apresentação das discussões em torno dos salões.

Para finalizar, é importante ressaltar que, segundo Canclini (2011, p. 69), esse tipo de modernização, de um mercado consumidor restrito, acaba por privilegiar minorias, sendo bom para a hegemonia das elites dominantes. A produção artística nesse contexto torna-se sacralizada, é produzida a partir de uma criação que diferencia arte e artesanato, fica restrita a coleções de museus e exige do público um comportamento de contemplação.

\section{O meio artístico e Nilo Previdi}

Mas o meio artístico apresenta algumas peculiaridades que não permitem uma análise homogênea com o resto do país, como foi feito com a questão da modernização de Curitiba. Aliás, essa é uma característica que já foi discutida, pois a cidade, embora apresentasse uma aparência moderna, tinha um mercado cultural deficiente e um meio artístico estagnado. Tratando-se das artes plásticas, o Paraná teve uma tradição arraigada no ensino de mestres acadêmicos e até a década de 1950 esteve isolada do que se produzia artisticamente no país e no exterior.

Dessa forma, pode-se começar a pensar em arte moderna ou em uma "consolidação do moderno", de acordo com Freitas (2003) entre as décadas de 1950 e 1960. Em 1960, enquanto alguns artistas locais - principalmente os que estavam gerindo a política cultural - travavam um embate em torno da legitimidade da arte abstrata em solo paranaense, no eixo Rio - São Paulo, para não falar no exterior, esse já era um assunto desdobrado em outras tantas vertentes de arte.

Mas não se pode falar em atraso de ideias, pelo menos não totalmente, pois no Paraná dos

\footnotetext{
${ }^{14}$ No caso de Curitiba e do Paraná, o Salão Paranaense de Belas Artes, criado em 1944
}

anos 1960 a oposição que se fazia era entre artistas abstratos e artistas figurativos, em um período em que já se contava com um maior número de informações vindas de fora. A defesa da figuração não era assunto exclusivamente local; além do mais, a questão do engajamento social, debatida localmente com base em ecos vindos de fora, relacionava-se a essa confrontação "arte pela arte" versus "arte figurativa". Na filosofia, esse era o assunto do momento na Europa, por exemplo, sendo uma de suas principais vozes Jean-Paul Sartre. ${ }^{15}$

Sartre é uma figura central na concepção de arte engajada. Em sua discutida obra Que é a literatura? o engajamento no campo das artes é apresentado ao leitor/espectador como um apelo, mas antes como fruto de uma vontade própria de seu autor que recorre à liberdade do público para que sua obra seja aceita e passe a existir como essencial. Ao considerar a obra de arte como um valor, justamente por constituir um apelo, Sartre (1999, p. 47) defende a ideia de que ela não se encerra em si mesma, mas retoma a totalidade do mundo, conforme se constata: "Pois é bem esta a finalidade última da arte: recuperar este mundo, mostrando-o tal como ele é, mas como se tivesse origem na liberdade humana".

No campo da dramaturgia são pertinentes as discussões realizadas em torno da temática social realista utilizada na representação teatral. Mais do que representação, trata-se de uma tentativa de interferência e suplantação da estrutura social vigente, sendo Bertold Brecht sua figura central. Conforme a leitura de Brecht (1957, p. 86), o homem pode conhecer a si mesmo através da literatura em um processo de evolução que só uma arte realista é capaz de dar, sendo o realismo um fundamento da arte que não pode ficar restrito apenas às discussões literárias, mas como uma atitude do artista em relação à sociedade, acrescentando que "Os nossos livros, os nossos quadros, os nossos teatros, os nossos filmes e a nossa música podem e devem contribuir decisivamente para a solução dos problemas vitais do nosso país" (Brecht, ibid.).

Amaral (1984, p. 315-316) destaca na arte brasileira três períodos em que a preocupação com a

\footnotetext{
${ }^{15}$ As formas de pensar e fazer artes plásticas, principalmente em 1960, encontram respaldo em outras formas de arte como no teatro e em um pensamento filosófico recorrente naquele momento, o existencialismo. O caderno Letras e \& Artes publicou uma série de matérias discutindo o existencialismo e o pensamento de Sartre.
} 
função social da arte se torna mais clara, associada a questões bem específicas e constituindo fases situadas no desenvolvimento do modernismo brasileiro. O terceiro período é o que corresponde à década de 1960, quando acontece uma participação conjunta entre a massa popular, os intelectuais e os artistas, buscando maior conscientização política e social. Esse é um momento marcante para o teatro, o Cinema Novo e a música popular. Registra-se também nesse momento a criação dos CPCs (Centros Populares de Cultura).

De que forma o artista Nilo Previdi pode ser útil para a compreensão do cenário descrito?

As ideias do artista iam ao encontro com dessa necessidade de fazer uma arte voltada para a transformação social. Suas ações foram voltadas, durante a década de 1960, para a arte figurativa, na qual a temática social foi uma constante, mas também através de projetos que visavam utilizar a arte para conscientizar socialmente as pessoas, principalmente por meio do Centro de Gravura, local que Previdi presidiu de 1950 até 1970 .

A postura de artista figurativo e suas ações no sentido de defender a arte engajada aconteceram em um cenário de disputas ideológicas. E, existia outra vertente, que pensava arte de maneira distinta - através da discussão puramente formal da obra, o que caracterizava o abstracionismo - e por meio de demarcações de lugares, uma vez que a política cultural dominante afirmava naquele momento a arte abstrata como arte moderna.

O que torna Previdi um agente interessante para este estudo é seu perfil moderno e engajado e o fato de que ele torna-se visível de maneiras diferentes a partir da posição que escolhe em relação à elite cultural dominante.

Uma década antes Previdi fazia parte do grupo de artistas modernos que pretendia disputar o Salão de Arte Oficial do Estado junto com os artistas mais antigos e conservadores, conhecidos como acadêmicos. Lembramos que a importância daquele espaço oficial era justamente dar visibilidade ao artista, que só encontrava uma forma de sobreviver da arte tornando-se professor. Essa deficiência no mercado comprador de arte já foi discutida e é mais uma característica do chamado "modernismo sem modernização". Trata-se da deficiência e da disparidade entre um desenvolvimento estético e o sistema econômico e social. Vimos no tópico anterior quanto a miséria cresceu junto com o progresso da cidade, e isso também implica a defasagem de um público apreciador e consumidor de arte.

Já em 1960 observa-se, no sentido exposto por Certeau (1995), uma estratégia para introduzir a arte abstrata no estado, que consistiu em ganhar espaço dentro da Instituição do Salão Paranaense para a partir dela impor uma política cultural. Alguns artistas ligados às correntes não figurativas da arte, quando conseguiram cargos de importância dentro da Secretaria de Cultura, passaram a influenciar a composição dos júris, a escolha dos artistas expositores, bem como a incentivar e a legitimar cada vez mais a arte não figurativa e a abstração, considerada naquele momento, como já falamos, o exemplo da arte moderna. ${ }^{16}$ As lutas não se travaram fora do Salão Oficial, por meio do debate instituído nos jornais como feito anteriormente, no processo do qual Previdi participou como agente ativo, mas partiram de dentro do certame oficial.

Previdi e os outros artistas defensores da figuração foram excluídos do debate aos poucos. Cada vez mais frequentemente obras abstratas ganhavam as premiações dos salões locais, na medida em que alguns artistas paranaenses tinham a possibilidade de sair do país e voltar com um olhar estético novo; outros, vindos de cidades diferentes começavam também a competir com os artistas locais.

A saída de Previdi do ambiente artístico oficial configura-se como uma retirada estratégica, pois não havia como competir em um meio dominado por uma política cultural e ideológica contrária. Além do mais, apesar de uma nova cultura estar sendo imposta a um público como uma estética nova, no sentido de moderna e portanto, mais "condizente" com a cidade moderna havia um público ainda acostumado com a estética anterior. Tal fato pode ser ilustrado com a seguinte informação, retirada de um jornal de 1963, consultado no acervo do MAC:

Para defenderem as suas posições, os intelectuais autores das deformações culturais recorrem às bienais de São Paulo, de Veneza e Paris. Esquecem-se de que as alienações dos artistas dos países desenvolvidos, ainda que não reflitam

\footnotetext{
16 A esse respeito, consultar respectivamente Geraldo Veiga Leão Camargo. Escolhas abstratas - arte e política no Paraná (1950-1962). Dissertação de mestrado em história. Curitiba: UFPR, 2002; e Lilian Hollanda Gassen. Mudanças culturais no meio artístico de Curitiba entre as décadas de 1960 e 1990. Dissertação de mestrado em História. Curitiba> UFPR, 2007.
} 
as dificuldades de grande parte das populações, pelo menos brotam de estágios mais avançados da sociedade humana; a presença de países subdesenvolvidos nesses certames se divide em duas partes: os "universais" que vivem com Pangloss o melhor dos mundos e dedicam abstrações aos seus compradores privilegiados e os conscientes, que refletem a vida e a alma de seu povo. Para exemplificar, logo depois de algumas requintadas exposições abstratas oficializadas, inaugurou-se em Curitiba a mostra de artistas mexicanos; o povo mostrou suas preferências apesar da pequena publicidade, o confronto ia do trágico ao ridículo.

Uma característica importante na análise do texto acima é a constatação de uma resistência situada no público, que deixou de reconhecer o valor da arte abstrata, embora oficializada, ou seja, legitimada, para prestigiar outro tipo de exposição, figurativa.

Mas uma análise mais profunda do meio artístico pode ser feita por meio do estudo do artista e da leitura de sua obra. A composição figurativa mostrada na [figura 1] foi produzida em 1963. Dela, algumas características do artista Nilo Previdi e do contexto podem ser levantadas.

Figura 1 - Sem título. Nilo Previdi, 1953. Foto e acervo Fernando Velloso.

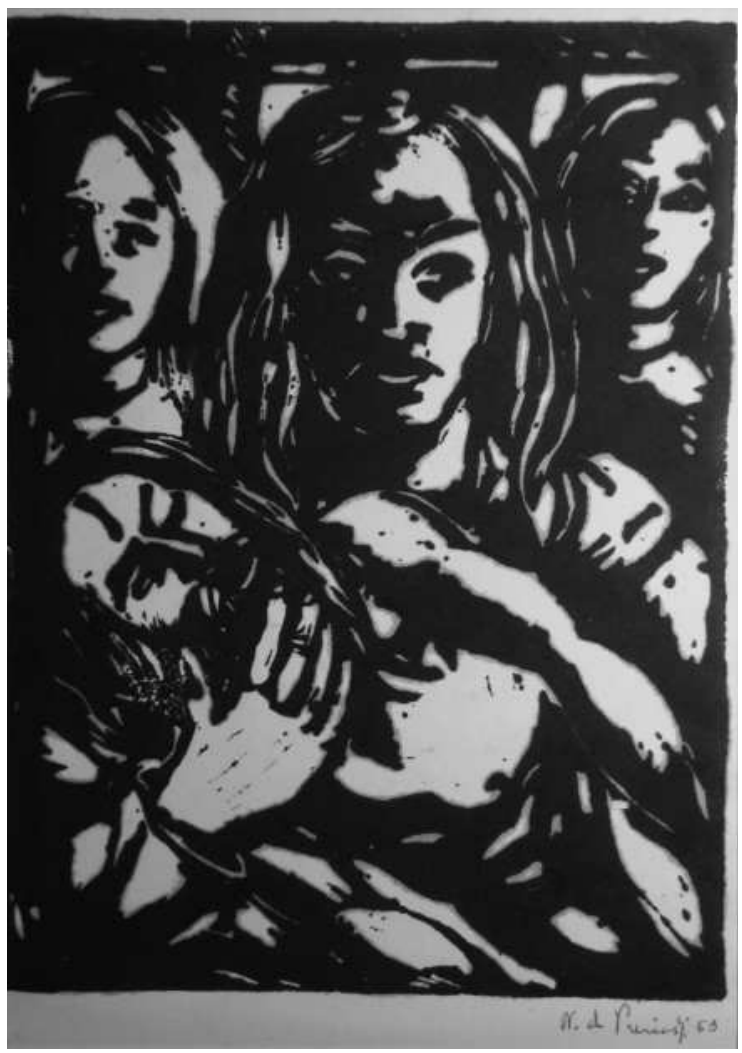

Inicialmente pode-se apontar uma relação interessante entre a arte da gravura e o desenvolvimento dos meios de comunicação de massa, característicos das décadas de 1950-60: a reprodução em série e a popularização da imagem, característica observável também na produção da gravura, que ainda apresenta um baixo custo de aquisição em comparação com sobra de arte como a pintura, aquela de dentro dos museus.

A presente gravura é do tipo xilogravura, obtida com o trabalho com a madeira, o que garante à impressão traçados grossos e o registro da textura da superfície trabalhada na folha impressa. ${ }^{17}$

A técnica da xilogravura era a utilizada por Previdi, pois podia ser feita com poucos recursos financeiros. As gravuras feitas com outras técnicas, como o desenho no metal, carecem do uso de ácidos e de uma habilidade apurada.

$\mathrm{O}$ artista se tornou conhecido por ensinar a técnica da xilogravura a pessoas comuns, que não conseguiriam trabalhar com o metal. O traçado grosso das linhas da composição confere a ela uma expressividade característica das obras expressionistas.

A recorrência ao expressionismo era característica comum nos anos 1960 no Brasil, ${ }^{18}$ sendo identificada na obra de outros gravadores de renome do país, caso de Goeldi, artista gaúcho. Mas é possível citar outros artistas ligados ao expressionismo, caso de Potty Lazzarotto e Portinari. Eles são exemplos daqueles que começam a explorar a temática social na arte, e a ela associa-se a imagem do artista engajado.

\footnotetext{
${ }^{17} \mathrm{O}$ leitor pode estar questionando o fato de se apresentar uma obra datada da década de 1950 e não 1960. Trata-se da preferência por mostrar obras assinadas e datadas de Previdi, pois muitas gravuras atribuídas ao artista não possuem esses importantes indícios. É possível afirmar que as gravuras de Previdi da década de 1960 (pelo menos parte delas) continuavam com as mesmas características expressas na imagem escolhida [figura 1], como mostram as pinturas do artista encontradas da década de 1960, que permitem verificar uma retratação do social bem próxima da gravura analisada. Outro fator importante a ser enfatizado é a falta de material sobre o Centro de Gravura e consequentemente sobre a ausência das gravuras produzidas no local. A maior parte das informações sobre o Centro de Gravura provêm das fontes orais e das gravuras obtidas de acervos particulares.

18 O caderno cultural Letras e/\& Artes trouxe entre 1960 e 1961, recorrentes referências ao expressionismo. O exemplar de 10 de abril de 1960 noticia o fechamento dos clubes de cinema e a exibição dos filmes expressionistas, "o cinema autêntico", nas dependências da Biblioteca Pública. Em uma edição posterior, de 22 de maio, o periódico continua divulgando a projeção dos filmes, desta vez menciona o cinema engagé, informando sobre o pequeno público presente nas sessões anteriores.
} 
A produção de Nilo Previdi segue, portanto, à margem da arte abstrata, mas situada na produção social do período. São características comuns na obra do artista, a exemplo da gravura selecionada, a deformação do traço, expressa nas formas irregulares da mão e dos rostos das pessoas representadas. Outro indício é a própria representação, sempre privilegiando um tipo humano: trabalhadores, lavadeiras ou simplesmente homens e mulheres, mas geralmente de uma condição social condizente com o trabalho representado.

$\mathrm{Na}$ imagem selecionada existe uma referência cristã, identificada pelo corpo prostrado na mulher e que ocupa o centro da imagem. Esse corpo, que parece ser a de um homem, se apresenta nu; seu cabelo comprido e a forma como ele está disposto lembra a representação de Cristo. Além disso, a maneira como o corpo é segurado pela mulher remete à figura de uma Pietá.

A obra permite pensar no discurso engajado do qual resultou. Trata-se da imagem que mais se aproxima do perfil do curitibano da periferia. Sendo assim, é outra representação da cidade dos anos 1960, que expressa através da xilogravura um retrato de povo. Da mesma forma que a imagem foi produzida pela incorporação de um discurso que se adequou ao contexto da cidade e da ideologia do artista, ela também se torna capaz de ser reelaborada pelo público receptor.

A questão apontada acima é de difícil mensuração, porém é possível pensar, com base nos exemplos já discutidos - sobre a cidade, a arte e o artista, que a arte figurativa, embora já ultrapassada no circuito oficial, encontrasse no público maior identificação do que a arte abstrata, o que confere a Previdi uma resposta positiva a sua aversão à tendência artística imposta: o abstracionismo.

\section{O Centro de Gravura}

Um apêndice da Escola de Belas Artes, um ateliê livre, o porão da Escola de Música e Belas Artes, o lugar onde serviam sopão aos pobres, ou uma célula comunista? Eu diria que o espaço durante os anos 1960 foi utilizado por Previdi a ponto de ele próprio se tornar uma referência para o lugar. Para Alcy Xavier ${ }^{19}$ era um espaço onde não existia uma preocupação doutrinal e o intuito era ensinar a gravura e na medida do possível dar noções de estética e história da arte. Xavier deu aulas lá, ensinando estética e desenho, enquanto Esmeraldo Blasi ocupava-se da história da arte e Previdi era responsável pela prática da gravura. Xavier confirma que eles tiveram cerca de 40 alunos, mas nada foi registrado; não havia interesse por parte dos professores em preservar a história do lugar.

Parte desse desprendimento dos artistas fundadores do Centro de Gravura colabora para que seja difícil abordar o local com precisão, uma vez que não existem registros escritos e que as informações das pessoas que conheceram o espaço sejam contraditórias. Através dos relatos de entrevistados que fizeram parte de uma geração posterior à de Previdi logo, que não viveram os tempos do Centro de Gravura é possível perceber que a imagem que ficou do lugar é a que se relaciona com o aspecto social.

$\mathrm{O}$ artista Alcy Xavier, que poderia explicar melhor essa fase relacionada às ações sociais do Centro de Gravura, sai de Curitiba no final de 1959, e afirma que ficou sabendo posteriormente da fama do lugar relacionado ao assistencialismo, mas não sabe dar informações sobre isso. De qualquer forma, é nesse período de 1960 que os jornais locais apresentam notícias sobre mostras de gravura promovidas por Previdi. Na mesma proporção em que o nome do artista aparece relacionado à promoção da gravura, ele se afasta do circuito oficial de arte, seu nome desaparece tanto das exposições realizadas pelo Salão Paranaense, como também das fichas de inscrição para o salão, o que comprova que ele não mandava mais trabalhos a julgamento.

Analisando o ambiente artístico de Curitiba no referido período por meio da leitura de Certeau (1995), é possível identificar a seguinte situação:

a) Nilo Previdi em 1960 se tornou marginal à política cultural imposta. Sua situação periférica não foi suficiente para seu afastamento total do cenário artístico, uma vez que, apesar do discurso oficial se manter à custa do poder das instituições (principalmente os salões oficiais de arte), outros artistas compartilhavam do pensamento de Previdi, além de um público que legitimava a arte figurativa, frequentando as exposições de gravura e o próprio ateliê no porão da EMBAP;

\footnotetext{
${ }^{19}$ Artista plástico (1933), entrevista concedida em 20 dez. 2011.
} 
b) Se o tipo de arte defendido por Previdi não encontrava mais espaço dentro do Salão Oficial, uma tática dele, residiu em buscar outros espaços para

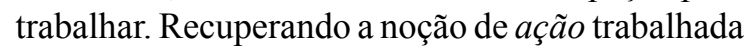
por Certeau, em que ele empenha um sentido militar ao termo, a noção de tática deve ser entendida como uma ação no campo do inimigo. Embora o Centro de Gravura tenha adquirido o status de ateliê livre, funcionava no porão de uma instituição oficial, a conservadora Escola de Música e Belas Artes. Dois são os momentos táticos de Previdi no Centro de Gravura: na década de 1950 enquanto se procurava legitimar uma arte moderna, livre do academicismo da EMBAP; e em 1960, produzindo uma arte figurativa e promovendo ações engajadas em um momento em que o circuito oficial buscava legitimar a arte abstrata;

c) O próprio caráter popular do espaço ocupado pelo artista (popular no sentido de ser uma alternativa de ensino ao espaço acadêmico, de difundir a figuração e de ser gratuito) torna-se também uma tática, dentro do meio artístico local, que oficialmente impunha uma arte cuja apreciação estética não alcançava o público como um todo.

Sem o antigo espaço ocupado no cenário oficial da arte, Previdi busca na década de 1960 outros lugares que lhe permitam exercer sua forma artística e seu modo de pensar. O Centro de Gravura funciona, assim, como a materialização do pensamento oposto ao da elite cultural dominante.

\section{Considerações finais}

O ambiente cultural da cidade de Curitiba, especialmente na década de 1960, apresenta contradições que são comuns ao contexto da América latina, somadas às peculiaridades do local. Tais contradições podem ser analisadas de diversas formas, sendo a abordagem cultural uma delas, através das teorias da cultura. Para este artigo duas opções foram feitas. Uma delas consistiu em escolher trabalhar com autores da história cultural, Certeau e Chatier. $\mathrm{O}$ estudo das maneiras como esses autores propõem estudar a cultura possibilitou abordar a cidade de Curitiba e o meio artístico, com base nas ações e práticas dos agentes culturais. O artista Nilo Previdi, principal personagem desta discussão, não foi tomado como um sujeito isolado, mas como aquele com potencialidade para, através de sua trajetória - que implicou tomada de posições e estratégias de ação em lugares de conflito -, revelar as tensões do seu meio.

A segunda opção foi tentar conciliar as ideias dos dois historiadores citados com as de Canclini, antropólogo, com o propósito de assimilar as contradições estudadas pelo autor no âmbito cultural massificado, de modo mais aproximado ao contexto latino e, portanto, ao ambiente de Curitiba.

É importante salientar que esta reflexão se fez na maioria das vezes por apontamentos que necessitam ser aprofundados. A maior contribuição de Canclini neste texto foi embasar a constatação de que no Brasil não se pode falar de uma cultura pura, sendo os hibridismos, ou qualquer outro nome que receba a fusão cultural, um fator importante para revelar contradições como as que foram citadas na Curitiba da década de 1960. Porém, a fusão entre cultura erudita, popular e massiva, neste artigo, foi utilizada para apresentar o contexto, uma espécie de "paisagem da pesquisa", sem que uma maior problematização fosse feita.

Da mesma maneira, alguns dos conceitos utilizados, principalmente os de Certeau, foram adaptados ao objeto de estudo. No texto exposto, a questão das táticas do consumidor foi substituída pelas táticas de Previdi como produtor. Não foi o objetivo dizer que a lógica do produtor é a mesma do consumidor, mas no contexto estudado o produtor cultural e consumidor (do meio cultural) Previdi passou por processos de interdição promovidos pela política cultural dominante, que o fizeram buscar meios, assim como os outros "consumidores" - , digo, apreciadores da arte e público em geral -, que desviassem a aceitação da arte abstrata como inovação e, de certa forma, como arte superior ou legítima.

A prévia constatação do muito que poderia ainda ser dito não serve como justificativa para o que não foi contemplado neste texto, mas reafirma as possibilidades de uso, ou para usar uma expressão inspirada em Certeau, reanima novos modos de produzir novos sentidos para os textos dos três autores citados em relação ao contexto descrito.

\section{Agradecimento}

Este artigo foi resultado de parte do desenvolvimento da pesquisa de mestrado em história pela 
Universidade Federal do Paraná (UFPR), iniciada em 2011 e ainda em fase de conclusão, intitulada "Nilo Previdi: contradições entre a arte moderna e arte engajada no Paraná entre os anos de 1950-60", que conta com o apoio financeiro da Capes.

\section{Referências bibliográficas}

AMARAL, Aracy. Arte para quê: a preocupação social na arte brasileira, 1930-1970. São Paulo: Nobel, 1984.

ANDRIOLI, Luiz. O circo e a cidade: história do grupo circense Queirolo em Curitiba. Curitiba: Edição do autor, 2007.

BACK Sylvio. Curitiba ao avesso: os subterrâneos do silêncio. Revista Panorama. n. 117. Curitiba: fev. 1962.

Letras e/\& artes. Cinquenta anos. Edição facsimilar. Curitiba: Diário do Paraná, 2011.

Brecht, Bertold. Estudos sobre teatro. Portugália: Editora LISBOA, 1957.

BOURDIEU, Pierre. O poder simbólico. Lisboa: Bertrand; Rio de Janeiro:1990.

CAMARGO, Geraldo Leão de Veiga. Escolhas abstratas, arte e política no Paraná (1950-1962). Dissertação de mestrado em história. Curitiba, UFPR, 2002.

CHARTIER, Roger. A beira da falésia: a história entre certezas e inquietudes. Editora da Universidade: Rio Grande do Sul, 2002.

DE CERTEAU, Michel. A cultura no plural. São Paulo: Papirus, 1995.

A invenção do cotidiano. Petrópolis: Vozes, 1998.

FREITAS, Artur. A consolidação do moderno na história da arte do Paraná, anos 50 e 60 . Revista de História Regional 8(2): 87-124. Inverno de 2003.

GASSEN, Lilian Hollanda. Mudanças culturais no meio artístico de Curitiba entre as décadas de 1960 e 1990. Dissertação de mestrado em história. Curitiba, UFPR, 2007.

SANTOS, Antônio de Almeida. Memórias e cidade: depoimentos e transformação urbana de Curitiba (1930-1990). Dissertação de mestrado em história. Curitiba, UFPR, 2005.

EISNER, Lotte. Gênese do filme expressionista. In: Back, Sylvio. Letras e/\& artes. Cinquenta anos. Edição facsimilar. Curitiba, Diário do Paraná, 10 abril de1960.

FOUCAUlT, Michel. A ordem do Discurso. São Paulo: Loyola, 1996.

LE GOFF, Jacques. Antigo/moderno. In: Enciclopédia Einaudi, v.1. Lisboa, Memória e História, 1997.
KAMINSKI, Rosane. Poética da angustia: história e ficção no cinema de Sylvio Back - anos 1960 e 70. Tese de doutorado em história. Curitiba, UFPR, 2008.

SARTRE, Jean-Paul. Que é a literatura? São Paulo: Ática, 1999.

Cinema engagé na bpp: vigo. In: Back, Sylvio. Letras e/\& artes. Cinquenta anos. Diário do Paraná. Edição facsimilar. Curitiba, Diário do Paraná, 22 de maio de 1960.

O Salão de Belas Artes. 5 dez.1963. Recorte de jornal da pasta do MAC, Museu de arte contemporânea do Paraná.

Sobre o plano Agache, consultar $<$ http://www.lolocornelsen. com.br>Acesso em 10, mai. 2011.

Artigo Submetido: 29/09/2012

Artigo Aprovado: 16/06/2013 